\title{
The Planning of Maintenance Support Capabilities of the Wartime Armored Equipment Autonomic Logistic System Based on QFD
}

\author{
Weilong Chen, Chunliang Chen, Wenhua Shi \\ Academy of Armored Forced Engineering, Beijing, 100072 ,China \\ chenweilong88@yeah.net
}

\begin{abstract}
In order to solve the problem of lacking development planning and unclear key development point for the wartime armored equipment autonomic logistic system, components, system structure, system requirements and competence objectives of the system is analyzed. A Quality Function Development model of the planning of maintenance support capability is put forward and solved. The result shows that information support capability, condition monitoring capability and reasoning capability are main influence factors of maintenance support capability of the wartime armored equipment autonomic logistic system.
\end{abstract}

Keywords- Autonomic Logistic System; Quality Function Development; maintenance support capabilities; Pareto

\section{INTRODUCTION}

Traditional passive-response support mode of armored equipment has some shortcomings, such as deficient predictability, bad pertinence and low support benefit. In order to solve these prominent problems, Autonomic Logistics ( AL ) $[1,2,3]$, which was first proposed when the U.S. F-35 fighter was developed, is studied by domestic scholars to impel equipment support reformation for armored equipment. However, current researches on armored equipment autonomic logistics just stay in stage of summary, including connotation, characteristics, key technology etc[4]. We still know little about how to plan and construct the system, not to mention the wartime one. In this paper, a quality function development(QFD) model of the wartime maintenance support capabilities is put forward, which is used to make a plan for capability construction of Armored Equipment autonomic logistics. This research has a certain theoretical reference value to construction of Armored Equipment Autonomic Logistic.

\section{ANALYSIS OF THE WARTIME ARMORED EQUIPMENT AUTONOMIC LOGISTIC}

\section{A. Definition, essence and advantages}

Aimed at restoring operational readiness of damaged equipments rapidly, the Wartime Armored Equipment Autonomic Logistic (WAEALS) makes use of sensors, which are installed in all parts of the vehicle body of armored equipment when it was designed and manufactured, to collect data from every components or subsystem. Then the prognostic and health management subsystem[5,6] deals with data through processing, transmission, inference and analysis, and accordingly predicts faults and remains life of equipments in real-time, generates maintenance strategy automatically, while support information is shared in realtime by all subsystem through the information support subsystem. Finally, damaged equipments are rapidly repaired by equipment repair subsystem.

The essence of wartime armored equipment autonomic logistic is to closely combine the intelligent self-diagnosis, real-time information support and rapid repair together, achieving the purposes of quickly restoring operational readiness of damaged equipments.

Compared with traditional support mode, the Autonomic Logistic has obvious advantage. First, faults can be noticed in time so that it can improve support pertinence and efficiency, as well as reduce costs. Second, fault diagnosis is accurate and highly automated. Third, it can improve rapid reaction capability and system flexibility of support, which meets the combat needs better.

\section{B. Analysis of WAEALS}

Since the Wartime Armored Equipment Autonomic Logistic System is a complex system, systematic engineering method is needed when we want to analyze it and make an appropriate plan to build system. Next, the system is analyzed from four aspects, components, system structure, system requirements and competence objectives.

First, components. Components, constituting the basis of WAEALS, is fundamental premise for system to exert whole function. They include the armored equipment subsystem, the prognostic and health management subsystem, the information support subsystem, material management subsystem, the resource delivery subsystem, the equipment repair subsystem and the support defense subsystem.

Second, function structure. The function structure of the WAEALS refers to subsystem division and its interrelationship. These subsystems are interconnected, interactional and mutual restrictive, working together for overall system function. Here, the system function structure is constructed, as Fig. 1.

Third, system requirements. System requirements of the wartime armored equipment autonomic logistic refers to necessary requirements which is essential to achieve the purposes of quickly restoring operational readiness of damaged equipments. They contain fast and accurate requirement-elicitation (represented by $\mathrm{R}_{1}$ ), correct decisionmaking and command $\left(\mathrm{R}_{2}\right)$, rapid and efficient repair $\left(\mathrm{R}_{3}\right)$, adequate and timely supply $\left(\mathrm{R}_{4}\right)$, comprehensive and lasting defense $\left(R_{5}\right)$. Each requirement involves several corresponding tasks as shown in table I. 


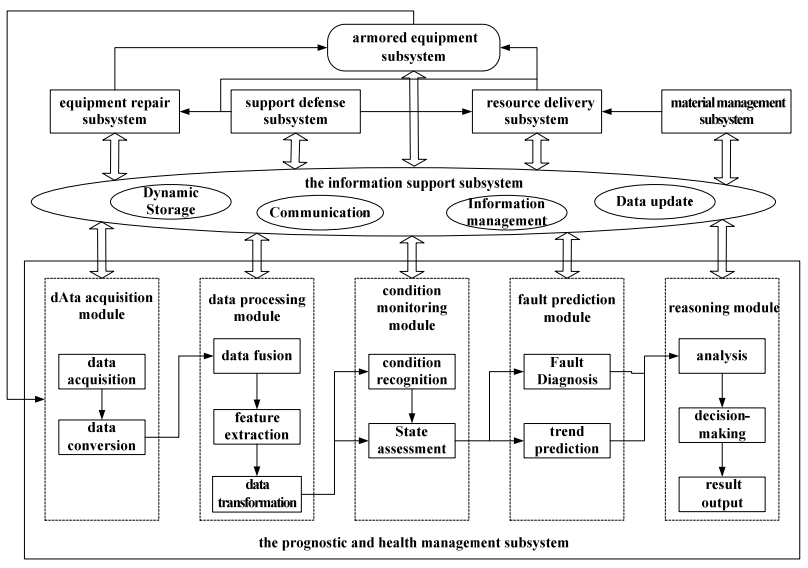

Figure 1. Function structure of the WAEALS

Fourth, competence objectives. Competence objectives of the WAEALS refers to these basic competencies which must be possessed in order to meet operational maintenance support requirements. They includes data acquisition and processing capability (represented by $A_{1}$ ), condition monitoring capability $\left(\mathrm{A}_{2}\right)$, fault prediction capability $\left(\mathrm{A}_{3}\right)$, reasoning and decision-making capability $\left(\mathrm{A}_{4}\right)$, information support capability $\left(\mathrm{A}_{5}\right)$, equipment repair capability $\left(\mathrm{A}_{6}\right)$, resource management capability $\left(A_{7}\right)$, delivery capability $\left(A_{8}\right)$, defensive and survival capability $\left(\mathrm{A}_{9}\right)$.

Among them, reasoning and decision-making capability $\left(\mathrm{A}_{4}\right)$ should be capable of comprehensively analyzing maintenance requirements and all kinds of realtime information, generating maintenance strategy automatically, assistant decision-making and commanding. Information support capability $\left(\mathrm{A}_{5}\right)$ is a kind of system capabilities, which can implement real-time visualization and share all information with each other through support information subsystem. The support information subsystem combines equipments, combat troops, manufacturer, supplier, management capability(A7) refers to the ability of support

\section{TABLE I. CORRESPONDING TASKS OF EVERY} REQUIREMENT

\begin{tabular}{|c|l|}
\hline requirements & \multicolumn{1}{|c|}{ corresponding tasks } \\
\hline $\mathrm{R}_{1}$ & $\begin{array}{l}\text { data acquisition and processing, fault detection } \\
\text { and isolation ,fault prediction, condition } \\
\text { monitoring }\end{array}$ \\
\hline $\mathrm{R}_{2}$ & $\begin{array}{l}\text { analysis and reasoning, generating maintenance } \\
\text { strategy automatically, staffing, resource } \\
\text { preparedness, directing repair activities }\end{array}$ \\
\hline $\mathrm{R}_{3}$ & $\begin{array}{l}\text { Maintenance module recombination, } \\
\text { using equipment and devices,implementing repair }\end{array}$ \\
\hline $\mathrm{R}_{4}$ & $\begin{array}{l}\text { Raising, reserving, presetting, management, } \\
\text { delivery }\end{array}$ \\
\hline $\mathrm{R}_{5}$ & defending delivery and maintenance \\
\hline
\end{tabular}

system to raise, store, preset and manage materials and equipments of maintenance support[7].

\section{BUILD OF THE WAEALS-BASED QFD MODEL OF PLANNING MAINTENANCE SUPPORT CAPABILITY}

QFD[8] is an analysis method, through which customer needs can be transformed into design and manufacture requirements. Its basic thought is to utmost satisfy customer requirements, based on understanding customer needs and meeting resource constraints. House of Quality (HOQ) is the core of QFD. In this paper, a WAEALS-based QFD model of maintenance support capability planning is constructed. Its House of Quality is shown in Fig. 2.

Here are problem-solving steps. First, identify the importance degree $w_{0}$ of various maintenance support requirements from combat support needs. Second, determine relation matrix $R$ between maintenance support requirements and its capabilities. Third, determine autocorrelation matrix $R_{c}$ of maintenance support capabilities. Fourth, determine the importance degree $W$ of maintenance support capabilities. Through the above steps, targeted planning schemes is put forward which meet the maintenance support requirements of the WAEALS.

\section{SOLUTION OF THE WAEALS-BASED QFD MODEL OF PLANNING MAINTENANCE SUPPORT CAPABILITY}

\section{A. Determine importance degree of maintenance support requirements.}

Analytic Hierarchy Process(AHP), with a scale of 1-3-5$7-9$, is used to determine importance degree of support requirements, when quickly achieving maintenance support goals and restoring operational readiness of damaged equipments is established as a criterion. The above five system requirements are analyzed and judgment matrix $A$ is constructed by maintenance support experts.

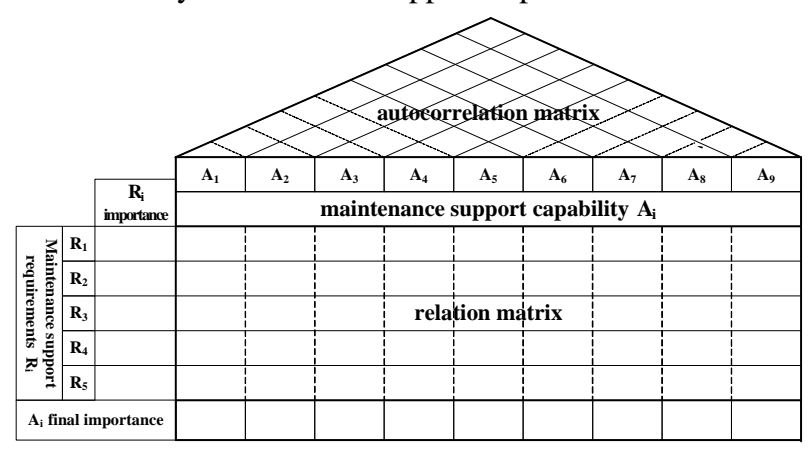

Figure 2. The HOQ of maintenance support capability planning 


$$
A=\left[\begin{array}{ccccc}
1 & 3 & 5 & 3 & 7 \\
\frac{1}{3} & 1 & 3 & 1 & 5 \\
\frac{1}{5} & \frac{1}{3} & 1 & \frac{1}{3} & 3 \\
\frac{1}{3} & 1 & 3 & 1 & 5 \\
\frac{1}{7} & \frac{1}{5} & \frac{1}{3} & \frac{1}{5} & 1
\end{array}\right]
$$

Calculated by Matlab, $\lambda_{\max }=5.1269$.

$$
\begin{aligned}
& C I=\frac{\lambda_{\max }-n}{n-1}=\frac{5.1269-5}{5-1}=0.0317 . \\
& C R==\frac{C I}{R I}=\frac{0.0317}{1.12}=0.0283 \leq 0.1 .
\end{aligned}
$$

Consistency testing of judgment matrix in AHP is acceptable[9]. Eigenvectors $x$ corresponding to $\lambda$ max can be evaluated. $x=(0.8424,0.3609,0.1549,0.3609,0.0767)$.

According to documentary [9], importance degree of maintenance support requirements is equal to Eigenvectors $x$.

$$
w=\lambda_{\max } .
$$

Normalized, $w=(0.4619,0.2010,0.0863,0.2010,0.0427)$

B. Determine importance degree of maintenance support capabilities.

Choose a scale of 1-3-5-7-9, which means that larger value, more related degree. Relation matrix $R$ between maintenance support requirements and its capabilities is analyzed and put forward by experts.

$$
R=\left[\begin{array}{lllllllll}
5 & 5 & 7 & 7 & 5 & 0 & 0 & 0 & 0 \\
1 & 3 & 3 & 7 & 7 & 5 & 0 & 1 & 3 \\
0 & 1 & 5 & 5 & 5 & 9 & 3 & 5 & 3 \\
0 & 0 & 0 & 0 & 7 & 5 & 5 & 7 & 3 \\
0 & 0 & 0 & 0 & 5 & 5 & 0 & 5 & 9
\end{array}\right]
$$

Therefore, the initial importance degree of maintenance support capabilities[10]

$$
W_{0}=W_{0} R
$$

$W_{0}=(2.5105,2.9988,4.2678,5.0718,3.0002,1.2639$, 2.2530, 1.8492)

As the above nine maintenance support capabilities are not independent of each other, autocorrelation matrix $R_{c}$ is constructed to correct the initial importance degree $W_{0}$. That is to say that the final importance degree of maintenance support capabilities[10]

$$
W=W_{0} R_{c} .
$$

Let $\mathrm{r}_{\mathrm{ij}}(1 \leq \mathrm{i}, \mathrm{j} \leq 9)$ be any one of $R_{c}$, where $r_{i j}=\left\{\begin{array}{c}1, i=j \\ k(0 \leq k<1), i \neq j\end{array}\right.$

experts as follow.

$$
R_{c}=\left[\begin{array}{ccccccccc}
1 & 0.5 & 0.5 & 0 & 0.4 & 0 & 0 & 0 & 0 \\
0.5 & 1 & 0.6 & 0.6 & 0.4 & 0 & 0 & 0 & 0 \\
0.5 & 0.6 & 1 & 0.5 & 0.2 & 0 & 0 & 0 & 0 \\
0 & 0.6 & 0.5 & 1 & 0.5 & 0 & 0 & 0 & 0 \\
0.4 & 0.4 & 0.2 & 0.5 & 1 & 0.3 & 0.4 & 0.2 & 0.2 \\
0 & 0 & 0 & 0 & 0.3 & 1 & 0 & 0.5 & 0.4 \\
0 & 0 & 0 & 0 & 0.4 & 0 & 1 & 0.3 & 0 \\
0 & 0 & 0 & 0 & 0.2 & 0.5 & 0.3 & 1 & 0.3 \\
0 & 0 & 0 & 0 & 0.2 & 0.4 & 0 & 0.3 & 1
\end{array}\right]
$$

Therefore, the final importance degree of maintenance support capabilities $W=W_{0} R_{c}$

Normalized, $W=(0.1074,0.1546,0.1400,0.1511,0.17327$, $0.0839,0.0540,0.0743,0.0620$ )

\section{ANALYSIS OF PLANNING RESULTS OF MAINTENANCE SUPPORT CAPABILITIES}

Pareto chart[11] is drawn as figure 3, according to the final importance degree of maintenance support capabilities which has been calculated above.

According to result of planning maintenance support capabilities, analysis principles of Pareto[12] and characteristics of the WAEALS, conclusions can be drawn.

1)As shown in the result, information support capability, condition monitoring capability and reasoning capability rank in the top three, which highlights real-time information support, intelligent self-diagnosis and self-generated maintenance strategy. These are typical characteristics of Autonomic Logistic.

2)The cumulative proportion ,which include information support capability, condition monitoring capability ,reasoning capability, failure prediction capability, data processing capability and equipment repair capability, is bigger than $80 \%$. They are main influence factors of maintenance support capability of the WAEALS, which belong to A factor.

3)The cumulative proportion, including material delivery capability, defense and survival capability and resource management capability, is $19.03 \%$. In principle, material delivery capability and defense and survival capability belong to B factor, second influence factor. At the same time, resource management capability belongs to $\mathrm{C}$ factor, general influence factors. However, the gap among the three is so small that it is inappropriate to divide them into B or C factor mechanically. The three capabilities could be grouped together to B factor, as second influence factor, which is more in comply with reality needs.

4)More attention should be paid to these $6 \mathrm{~A}$ factors because they have a major impact on system functions as a whole, when making development plans of maintenance support capability. In addition, the larger proportion factor occupies, the more input it needs. However, in this research, there are more than three A factors, and proportions are not very different to each other. The 6 maintenance support capability should be comprehensively constructed instead of only focusing on several of the first. At the same time, even though B factor is less important than A factor, B factor is still integral to the wartime maintenance support capability, 
which also should be paid enough attention in order to achieve coordinated development when planned and constructed.

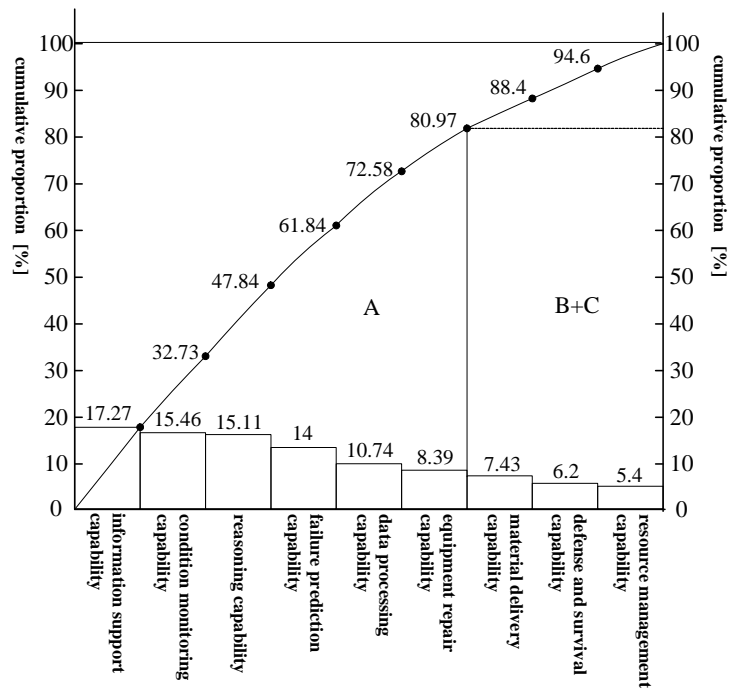

Figure 3. Pareto chart of maintenance support capabilities planning

\section{CONCLUSIONS}

Autonomic Logistic represents the development direction of 21st century equipment support in a certain extent. It is beneficial to learn Autonomic Logistic from the U.S. F-35 fighter, which will in favor of enhancing our armored equipment support capability and speeding up the information construction of equipment support system. The author conducts a preliminary study on the planning of maintenance support capability of the wartime armored equipment autonomic logistic by using QFD model. Next research will focus on how to quantitatively implement autonomic logistic in an armored brigade. The solution to this problem can provide a useful reference for the practical implementation of armored equipment autonomic logistic.

\section{REFERENCES}

[1] Dreyer, S.L, “Autonomic logistics-Developing an implementation approach for an existing military weapon system," Instrumentation \& Measurement Magazine, vol. 9, pp. 16-21, 2006.

[2] Carole Hedden, "THE LIGHTNING APPROACH TO MRO," Overhaul \& Maintenance. Washington, vol. 13, pp.1-2, 2007.

[3] Jingming Mao, Jiachang Xu, "system of Automotive Weapon Equipment,” Ordnance Industry Automation, vol. 28, pp.23-25, 2009.

[4] Yanhua Cao, Chunliang Chen, Jinghua Song, "Analysis on Autonomic Logistics Key Factors of Armored Equipment,” Journal of Academy of Armored Force Engineering, vol. 24, pp. 7-11, 2010.

[5] Bo Sun, Rui Yang, Jingsong Xie, "Research and application of the prognostic and health management system,”. Systems Engineering and Electronics, vol. 29, pp. 1762-1767, 2007.

[6] Zhiwei Liu, Rui Liu, Jingsong Xu, "Research of complex system's prognostic and health management ," Computer Measurement \& Control, vol. 18, pp. 2687-2689, 2010.

[7] Hang Xu, Chunliang Chen. Euipment Efficient Support Generality, Beijing, China: National Defence Industry Press,2012.

[8] Hailin Wang, Yan Hou. Modern Quality Management, 1st ed. Beijing, China: Economic Management Press, 2005, pp.153-154.

[9] Chengxian Yang, Qi Zhang, Huanliang Li. Theory and Technique of Quality Control in the Production Process of Mechanical Equipment, Beijing, China: National Defence Industry Press,2006.

[10] CHAN L K, WU M L, “A systematic approach to quality function deployment with a full illustrative example,” Omega, vol. 33, pp. 119-139, 2005.

[11] Hua Wang, "The application of the permutation picture method in project management," SHANXI ARCHITECTURE, vol. 34, pp. 195196, 2008.

[12] Dongqing Huan, "Statistical Analysis Method for Quality Control of Subway Vehicle Maintenance,” RAILWAY LOCOMOTIVE \& CAR, vol. 25, pp. 69-60, 2005. 